\title{
Research on the Current Situation and Countermeasures of Ecological Agriculture Development Management in Huadian
}

\author{
Xiaoqian $\mathrm{Wu}$ \\ School of Economics and Management, Beihua University, Jilin, Jilin, 132000, China \\ 21329576@qq.com
}

Keywords: Huadian City; Ecological agriculture; Agricultural economy; Sustainable

\begin{abstract}
Huadian City actively responds to the call for sustainable development of the central government and the relevant policies of the provincial government, attaches great importance to ecological construction, adheres to the development strategy of the "ecological establishment of the city", makes sustained efforts and has achieved remarkable results. However, the development of ecological agriculture in Huadian belongs to the trial stage, and there are still many problems. In this paper, the document method, field investigation and other research methods are used. Taking the ecological agriculture of Huadian as the research object, the present situation and existing problems of the development of ecological agriculture in Huadian are summarized and analyzed, and some specific suggestions are put forward for the development of ecological agriculture, hoping to provide theoretical basis and practical reference for the development of ecological agriculture in Huadian.
\end{abstract}

\section{Introduction}

Agriculture is the foundation of a country, and only when the agriculture is well developed can the country thrive. The report of the 19th National Congress of the Communist Party of China pointed out that the reform of ecological civilization system should be sped up, man and nature are life communities, and human beings must protect nature. It is obvious that the ecological civilization has been placed in the important position of the socialist construction. The ecological agriculture construction can provide the citizens with the safe ecological products and the beautiful ecological environment, in order to meet the higher demands of the citizens for the modern life. Huadian City adheres to the development strategy of "ecological city", persists in force, vigorously implements the ecological restoration project dominated by collecting and returning forest, combines afforestation with green beauty in urban and rural areas, strives to improve the ecological environment of urban and rural areas, and has achieved remarkable results. However, the development of ecological agriculture in Huadian belongs to the trial stage, and there are still many problems. It is urgent to explore the mode suitable for the development of modern ecological agriculture in Huadian. This paper puts forward specific suggestions for the development of ecological agriculture, and hopes to provide a theoretical basis for the development of ecological agriculture in Huadian.

\section{The Overview of Ecological Agriculture Development}

The Concept of Ecological Agriculture. American soil scientist Willian Albrecht first proposed the concept of eco-agriculture in 1970. Willian Albrecht believes that eco-agriculture does not use or use a small amount of growth regulators, such as fertilizers and pesticides, relying mainly on crops and the surrounding environment to make up for each other's supply[1]. In 2011, China Industrial Research Reports Network made a more complete definition of the concept of ecological agriculture, that is, ecological agriculture is an important mode of agricultural development. It presupposes the protection and improvement of the ecological environment. In accordance with the laws of ecological economics and ecology, modern science and technology and systematic methods are used to carry out intensive production and management [2]. Luo Shiming, president of the South China Agricultural University and professor of ecology, believes that consciously applying the 
principles of ecology to production, and at the same time, the agriculture that covers the ecological benefits in the development goals can be called ecological agriculture. From this we can see that China's definition of ecological agriculture has deeper connotations, and it has been continuously improved and continuously adapted to the development of China's national conditions.

The Necessity of Strengthening Ecological Agriculture Construction. The development of ecological agriculture is a necessary choice to improve rural productivity. With the reform and opening up and government support, rural productivity in Huadian City has greatly improved, but at present, the division of agriculture is too small, the advanced technology brought by the small-scale operation pattern is difficult to operate, the cost is high, and the problem of low income still exists. Under this situation, the current agricultural development should fully realize modern agriculture on the basis of stable household contracting management. Socialized large-scale production requires the operation of eco-agricultural industrialization. It aims to increase the overall efficiency of agriculture. Relying on leading enterprises, it will implement regional distribution, specialized production, and enterprise management, socialized services, and integrated management, and realize industrialized operation organizations.

The development of ecological agriculture is a necessary way to improve the competitiveness of agricultural products. China's agricultural operations are small in scale, low in organizational level, and weak in economic strength, which in turn leads to the fact that the quality of agricultural products is not too rigid and does not have the ability to compete with the international market. Under such circumstances, the development of agricultural industrialization operations will bring together scattered rural households to form market competitors with powerful technology and scale, and adjust the scale and standards according to the needs of the international market.

\section{Status Quo of Ecological Agriculture Development in Huadian City}

Huadian City is a small but beautiful and rich county-level city under the jurisdiction of Jilin City. Huadian City is known as the "eight mountains and one water and one field". In recent years, Huadian City has attached great importance to ecological construction, adhered to the development strategy of "Ecological Establishing the City", continued to exert force, and vigorously implemented ecological restoration projects led by clearing and returning forests, and combined afforestation and afforestation with urban and rural green beauty. The improvement of urban and rural ecological environment has achieved remarkable results.

Forest Town Construction. The forest town of Huadian City is located in Erdaodianzi Town, with a total investment of more than RMB 700,000. The main construction contents include: building 3 places of leisure square in town, setting up 35 sets of fitness equipment, building 9 flower beds in residential area and main street, planting flowers and lawn 1,250 square meters; planting 68300 trees on both sides of river embankment and main residential areas(including 6,300 trees, 6,2000 shrubs) and 670 meters of the river in the town were revamping to improve the capacity of flood control in the town, and the surrounding woodland of the town was reformed, and sea buckthorn fruit and flat European hazelnut were planted in 13 hectares, so that the economic benefits and ecological benefits were combined with each other[3]. At present, after a series of transformation, forest town construction has taken shape.

The Construction of the Demonstration Village of Green Beauty. The construction of green and beautiful demonstration villages in Huadian is implemented on the basis of new rural construction, with a focus on 7 townships and 12 villages in Huadian. The total investment of the project is 1.2 million yuan, which is based on the different characteristics of 12 villages. Through scientific planning and design, the trees, shrubs and flowers are properly matched in the Main Street Road, Lane Road, and Tuenwei to achieve overall greening. At present, the demonstration projects of green beauty in 12 villages have been completed in accordance with the design plan, and the greening effect has initially appeared, and the living environment in the village has been significantly improved. 


\section{The Problems in the Development of Ecological Agriculture in Huadian}

The development of ecological agriculture is a new agricultural revolution in China. Although some achievements have been made in Huadian, it is still in the initial stage of exploration. It is still facing many difficulties and problems, and the construction of ecological agriculture is a long way to go.

Lacking of Ecological Concept and Having Low Enthusiasm. The ecological concept has not been deeply rooted in the hearts of the people. For farmers in Huadian, in order to ensure high prices and high yields, they use chemical agents such as pesticides and fertilizers. They fail to realize the importance of quality and safety, and fail to realize that environment and resources are priceless. For farmers, when it comes to ecological operations, they immediately complain about more investment and more complicated operations. From the perspective of short-sightedness, which saves resources, simplifies labor, and blindly pursues immediate economic interests, they are more inclined to those technologies that are quick and cost-effective [4].

The Imperfection of Policy Support and Mechanism. Agricultural construction in Huadian relies mainly on the promotion of government administrative means, and the support and regulation system for ecological agriculture has not yet been established. At present, there are some policies that are not conducive to the development of ecological agriculture. For example, the use of pesticides in Huadian is in the forefront of our province. The high input of chemical fertilizer and pesticide for high output of agricultural products is the policy [5] that Huadian even persisted in our country for a long time, and of course, Huadian is no exception. In addition, without the input of government financial funds, it is impossible to develop ecological agriculture. The shortage of funds is a key issue in the development of ecological agriculture in Huadian. It is difficult to apply for funds to the state for a long time, and the supporting funds are not timely. In addition, the relevant supporting system for ecological agriculture construction in Huadian is not complete enough. The illegal use of land, the "three wastes" pollution and other illegal phenomena cannot be seriously punished, the lack of a more integrated ecological agricultural product and supply and marketing structure, ecological agricultural construction of the complete supporting service system is not complete [6].

The Lack of Professionals. The key reason for the slow development of eco-agriculture in Huadian City lies in the shortage of talents. There is a shortage of professionals who lack expertise in ecological agriculture in the existing rural labor force. Nowadays, many colleges and universities in China have set up specialties such as environmental protection and ecology to export specialized ecological management talents for the society. However, these professions focus more on theoretical training. The cultivation of skills such as practical operations still needs to be improved. This has led to the graduates' lack of comprehensive ability to engage in ecological agriculture. Even if some graduates with strong abilities have returned to Huadian City, The ambition is even rarer.

The Degree of Crackdown on the Law is not enough and There is Re-ploughing Rebound Phenomenon. The crackdown on law is not enough. There are problems with penalizing and undermining and it is difficult to play an effective deterrent effect. The reasons for the problems are as follows: First, the law enforcement of the cases of clearing and returning to forests is not enough. There are also phenomena of public security agencies bail pending prosecution, procuratorates not prosecuting, courts deferring and fines, etc. The law enforcement agencies have not uniformly enforced standards, and some cases have been compared and investigated very slowly. Second, there are fears and difficulties in some cadres, fear of offending people, affecting the effectiveness of the work. Some farmers are driven by interests, there is still a sense of resistance on the ideology, wait-and-see comparisons, and the rebound phenomenon of re-ploughing has not been completely eliminated [7]. 


\section{Suggestions on the Development Model of Ecological Agriculture in Huadian City}

Strengthening the Public Ecological Concept. The term "ecology" was mentioned several times in the report of the 19th National Congress of the People's Republic of China. This shows that the government attaches importance to and supports the ecological construction. To strengthen the concept of ecological agriculture, first of all, we must carry out the education of sustainable development. From teenagers, we should popularize ecological knowledge, advocate clean production and consumption concept, and promote the improvement of people's ecological consciousness level [8]. Second, we should mobilize farmers' enthusiasm for eco agricultural construction through publicity. In order to do a good job in the education of farmers and farmers and mobilize farmers to actively participate in the construction of ecological agriculture, we should make full use of big data means such as television, radio and We Chat micro-blog. It is of great significance to protect the ecological environment and build the agricultural environment with multi form, multi angle and full coverage.

Implementing the Strategy of Ecological Transformation. We will strengthen ecological reconstruction, reduce ecological degradation, and achieve economic and environmental win-win results. According to the development experience of foreign ecological agriculture, Huadian City has advocated the concept of ecological civilization in the construction of ecological agriculture development model, firmly convinced that man and nature are the concept of fate community [9]. We must promote the sustainable development model, eliminate short-term ideas that value only the economic interests of the present generation and ignore the survival benefits of future generations, integrate environmental protection and ecological construction into agricultural development, and accelerate the ecological transformation of agriculture.

Improving the System of Policy and Regulation. We must formulate laws and policies, establish incentive mechanisms, and promote and guide the development of legalization and standardization of eco-agriculture in light of their actual development. Through policy support, such as strengthening subsidies and taxation, we should make full use of economic means to guide the development of ecological agriculture. We establish an incentive mechanism to regulate agricultural producer behavior [10]. Through legislation and on the basis of making the relevant regulations of Huadian, we should also involve the planning system for the development of ecological agriculture, the industrial guidance system, the public participation in making the ecological environment paid use guidance, the ecological compensation system and so on. At the same time, the relevant laws and regulations should be perfected, and the relevant supporting systems should be formulated, such as the measures for the management of ecological agricultural production in Huadian, and the measures for the audit of clean production in Huadian.

Improving the Market Operation Mechanism. Huadian city should play the role of Industry Association and rural economic cooperation organization, guide the main body of ecological agricultural product market to improve the system of recycling, processing and sales, reasonably reduce the operating cost, expand the scale of operation, guarantee the quality of the market service, increase the trust of the consumers, improve the quality of the agricultural products through various changes and strive for the upstream of the agricultural product market. We will further accelerate the standardization of the ecological agricultural market in Huadian and establish a new marketing mechanism, such as membership system, direct selling model, product identification system, e-commerce network and ecotourism marketing. We should optimize the price formation mechanism of agricultural products, achieve high quality and high price, and ensure the reasonable returns of ecological agriculture.

\section{References}

[1] Lishuang Zuo: Research on the Development of Eco-agriculture in Changchun[D], Jilin Agricultural University, 2015(6):7.

[2] Suling Guo: Development Prospects and Countermeasures of Ecological Agriculture under the New Normal Situation -- Taking Henan Province as an Example[J], Chinese Journal of 
Agricultural Resources and Regional Planning, 2016(1).

[3] Huadian City Government Website.

[4] Tao Hu: Coordinate Agricultural Policies and Environmental Policies and Protect Rural Ecological Environment[J], Agro-Environment and Development, 2015(10):25.

[5] Ke Tang: The Strategy of the Construction of Modern Ecological Agriculture in China[M], China Agriculture Press, 2015(6):30.

[6] Jian Li and Hui Zhou: Research on the Operation Model of Agro-Ecosystem Oriented on Circular Economy[J], Soft Science, 2017.21(4).

[7] Yangying Gan, Zhuhua Su, etc: Study on the Development Plan of Ecological Agriculture in Lian Ping County, Guangdong[J], Chinese Agricultural Science Bulletin, 2017(3).

[8] Haixin Qiao and Yanhua Wang: Comprehensive Benefit Evaluation of Agricultural Production in Jilin Province -- An Empirical Analysis Based on Principal Component Analysis[J], Journal of Jilin Agricultural University, 2014(8).

[9] Songxu Wang and Weiyun Chi: Natural Resource Utilization and Eco Economic System[M], China Environment Press, 1992.

[10] Jiandong Li: The Theory and Practice of Ecological Environment Construction in Jilin Province[M], Beijing: Jilin Science \& Technology Publishing House, 2005. 